pretend that small differences are likely to be used by anyone as determinants of life or death. He nevertheless makes some excellent points (for example, should a marginal difference for a very large number of people outweigh substantial gains for a few?) and is perfectly entitled to maintain that a lottery is ultimately the only fair method for determining who has access if not all can be treated.

Lockwood also deals with QALYs, and the running battle between Williams and Harris. He suggests that a principle of justice that is fundamental to the Hippocratic tradition - namely 'to each according to his need' - should act as a constraint on Williams's welfare maximisation principle. Broome is similarly concerned with the balance between maximising and fairness, contending that both have to be weighed and that they normally pull in different directions. Neither is overriding, and it will almost certainly be right to trade off some of one against the other. He sees QALYs as a valuable, but in the end fatally flawed, attempt to assess good in medical contexts.

It seems to me a pity during this high quality academic debate about the theory of QALYs that relatively little attention is being given to improving the data on which they are based, and virtually none to their appropriate use. For example it makes all the difference in the world whether they are used to assess competing therapies for the same patient or to decide between patients, whether they are used primarily to jolt us into asking whether the historical allocation of resources seems seriously out of line with rationality and justice, or whether (as most commentators appear to assume) QALYs are to be fed into a black box somewhere from which will come a resource allocation printout to be applied slavishly to clinical choices. QALYs can be improved. With improvement they will be a helpful aid to questioning. They must never be used as a sole criterion nor as a mechanical substitute for informed and compassionate human judgement.

The essays that do not deal with the volume's dominant theme are the ones by Weale, Goodin and Hollis. Weale raises the neglected question of what is due to providers and how, in a system subject to the monopoly bargaining power of the state, we can achieve justice in the incomes paid to those who work in the National Health Service. Goodin argues (in relation to heroic therapies) that there should always be a presupposition against heroic intervention if only because it raises false hopes. Hollis, with a delightfully written case-study, discusses two dilemmas of the physician. The first is the responsibility to weigh what the physician thinks is in the patient's best interests versus what the patient appears to want - one would have to have very compelling reasons to override the latter. The second is the two-fold loyalty to the patient and (when resources are stretched to their limit) to the community. This second dilemma is highly relevant to the current emotionally charged debates about doctors as budget-holders. There are no simple solutions to this, but also no escape.

The volume includes one perfectly delightful typo. We are told that instead of QALYs 'a weighted lorry would be fairer'. For lorry, read lottery. Nevertheless it is a memorable image.

ROBERT J MAXWELL Secretary/Chief Executive, The King's Fund, 14 Palace Court, London W2 4HT.

\section{Follies and Fallacies in Medicine}

\section{P Skrabanek and J McCormick, 170 pages, Glasgow, £7.95, Tarragon Press, 1989}

The Dublin-based authors of this witty, lucid and intentionally provocative treatise have recently acquired a certain amount of notoriety as contemporary scourges of inflated medical egos. They are not alone in attacking past and present claims made for or on behalf of clinical medicine to have been the major instrument of greater longevity, nor in showing how fallacious and flimsy have been and still are some of the claims of medical notables to knowledge of disease processes and the efficacy of therapeutic measures. They number themselves proudly among the 'abominable "no-men",

However, in this book, and elsewhere, they have other targets. They have turned on their allies in some of the iconoclastic arguments - that is on protagonists of public health and preventive medicine on the one hand and proponents of alternative medicines on the other - and accused them of allowing their morally-inspired zeal for social betterment as they see it to outweigh sober scientific judgement. In so doing, they imply that many contemporary health zealots are imposing their own moral standards on many innocent people who may be duped into foregoing harmless hedonistic practices which are unlikely to shorten their life-spans significantly or reduce the overall quality of their existence.

The book has six chapters. The first deals with placebos. The authors claim that a large element of modern therapeutics is no better than a placebo, but that this is virtually concealed from medical students and is inadequately researched. As a result they imply that a measure of self-deceit is rife among medical practitioners as well as deceit of patients; but they do not make clear whether in eliminating the first - selfdeceit - which they advocate, presumably by inducing greater scepticism and understanding of the nature of therapy, practitioners' will no longer be on the horns of their moral dilemmas.

The second chapter lists and describes 26, somewhat broadly defined, fallacies commonly observed in medical reasoning. In at least one listed case, that of randomised controlled trials, the authors suggest that not all the reputedly ethical arguments that have been used against conducting them have been genuine and justifiable. Rather they are advanced, it is claimed, by those who wish to defend existing practices.

The third chapter is concerned with the temptation to diagnose and treat when doctors are faced by conditions whose causes cannot be ascertained. Diagnosis of, as the authors call it, nondisease, enhances the power which can be exercised over patients. The consequent labelling can itself damage, potentially irrevocably. 'All therapeutic activity directed at non-diseases is harmful; sometimes the harm is substantial' is their main conclusion.

The fourth chapter examines some recent developments in preventive medicine, which they claim have been largely exempt from ethical consideration. Their targets in the chapter are those who would change the diets of whole populations as well as the proponents of wholesale screening for breast and cervical cancer and the treatment of slightly elevated blood pressures. They see in it the potentially malign influence of the all-powerful state which seeks better to control its subjects and utilises the medical profession so to do. They conclude categorically that, while it is legitimate for doctors to maintain 'a certain modicum of therapeutic optimism when caring for the sick' (for example the cancer sufferer), the extension of 
such scientifically unsupported optimism into the domain of preventive medicine 'cannot be justified'.

The fifth chapter, on alternative medicines, pours scorn on their pseudoscientific claims. It attributes any efficacy which they may have to the placebo effect, which, once again, they appear to denigrate as being inconsistent with honesty, which they rate highly, and with truth based on scientific evaluation.

Their sixth chapter and the concluding Envoi return to the issue of the morality of modern medicine. Insofar as it has had a successful impact, they attribute it to its pursuit of truth, a pursuit which they see as embodied in the scepticism of basic scientific methods, a scepticism which they regard as virtually absent from presentday medical education.

Many of the ends of their controversial statements are by no means tied up and convincing. For this reason, perhaps, it could usefully become a text to encourage the medical profession's neophytes to think more deeply about the moral and social consequences of the trade they are learning. It is to be hoped, however, that the arguments they use so appealingly will not be accepted without themselves being subjected to the scepticism and criticism of received wisdom which they advocate.

MARGOT JEFFERYS Emeritus Professor of Medical Sociology, University of London

\section{Medical Ethics and the Value of Life}

Edited by Peter Byrne, 162 pages, Chichester, £13.50, John Wiley and Son, 1990
This latest volume in the excellent series edited by Peter Byrne will prove of most use and interest to those engaged in the teaching of medical ethics. The style and academic level of the articles included ranges from the chatty and anecdotal to the philosophically demanding, thus allowing the teacher to extract material appropriate to a variety of audiences.

The first topic raised in the volume is that of euthanasia. $\mathrm{H} \mathrm{J} \mathrm{J} \mathrm{Leenen} \mathrm{offers}$ an informative account of the current Dutch position on euthanasia and the political and legal debates surrounding the issue in that country. The article is less useful as an account of the ethical issues involved, as the author, an obvious proponent of euthanasia, tends to dismiss his opponents' arguments rather too easily. Peter Byrne's article however, which discusses the recent BMA report on euthanasia, is an excellent introduction to the issues involved and the philosophical arguments employed in this area. I expect to find this article particularly helpful in a teaching context; similarly Basil Mitchell's article on the value of life, which is a clear and concise account of the opposing views held on the subject. Although the author fails to reach any great conclusions himself, there is no evidence of the 'dreary confusion and obtuseness of mind' he apologises for at the beginning of the paper.

In his preface the Editor warns that Sophie Botros's article, 'Abortion, Embryo Research and Fetal Transplantation' will prove challenging, and I suspect many readers will consider this an understatement. This is a difficult paper, deserving careful attention, which it may not receive in this context, and I question the decision to include it.

I would also wish to make a more general criticism concerning the selection of articles. The Editor explains that the volume 'covers a wide range of issues while focusing on a series of related themes', with some issues being carried over from earlier volumes of the series. The inclusion of two papers on the teaching of medical ethics results from the Editor's probably correct belief that the BMA report on euthanasia 'fuels doubts about whether philosophers and reflective medical practitioners can communicate successfully'. Roger Higgs raises the question of whether medical ethics can be taught, a question that will interest both ethicists and medical practitioners. Raanan Gillon offers his impressions on the teaching of medical ethics in the United States. Gillon's article is interesting, especially to those attempting to teach the subject in this country, but I felt the pages could have been better used to discuss issues more obviously related to the central theme of the volume. I had similar doubts concerning the Bishop of Oxford's paper which called for tolerance to be shown towards people with AIDS. Although I welcome such a message from a leading churchman, I felt his paper added little to the coherence of the volume as a whole.

Given the enormity of the ethical issues surrounding euthanasia, and the broader issue of the value of life I would have preferred to see more space being devoted to these subjects. Having said this, I enjoyed the two remaining articles, Albert Weale's discussion of resource allocation within a democratic system, and John Mahoney's exploration of whether or not it is right to allow parents to select the sex of their children.

CALLIOPE FARSIDES Department of Philosophy, University of Keele 